\title{
A Basic Analysis Of Aging Aircraft, Region Of The World, And Accidents
}

Jorge M. Herrera, D.B.A., Embry-Riddle Aeronautical University, USA Bijan Vasigh, Ph.D., Embry-Riddle Aeronautical University, USA

\begin{abstract}
Differences in aviation safety records around the world should be minimal or nonexistent considering the global nature of aviation. However, significant differences exist and the reasons for those require the attention of governments, regulatory agencies, aircraft manufacturers, airlines and the flying public. One concern is that aircraft are increasingly used beyond their designed economic life. This study focuses on the relationship between aging aircraft and the country where the aircraft was registered. Findings support the idea that in general, the frequency of accidents increases with the age of an aircraft. The study also revealed that there is a correlation between the number of accidents, their severity and aircraft manufacturers. The aircraft's phase of flight was also related to the number of accidents, with the Approach/Landing phase having the greatest number of accidents. The FAA and JAA have been influential in the development and dissemination of safety programs around the world. However, their efforts have not yet resulted in a world-wide standardization of safety and maintenance programs. This may be an indication that while an aircraft may be a global product, the aviation industry lags behind in becoming a global industry.
\end{abstract}

\section{INTRODUCTION}

$\mathrm{t}$ is well known that transportation technologies have been a major factor in the speed at which globalization has increased in recent years. However, the aviation industry itself may not have experienced the globalization it has facilitated in other industries in the world's economies. An aircraft today should be as good an example of a global product as one could find. Differences in the safety record of aircraft around the world should be negligible, as aircraft regulation, along with other practices, would be expected to have reached a high level of standardization. However, differences in accident rates among countries where aircraft were registered indicate that this may not be the case. It is important to investigate the reasons for those differences and consider ways to close the gap in safety records among countries. This study is of importance to the traveling public and all other stakeholders, including federal regulators and financial economists in the industry.

The purpose of this work is to study the relationship between accidents due to aging aircraft and the countries where the aircraft were registered. Anecdotal evidence indicates that there may be significant differences in the aircraft maintenance practices among various countries of the world. One concern is that when an airline reduces the average age of its fleet by transferring its older aircraft to another country, it might inadvertantly transfer the risk of accidents because that country may not have adequate aging aircraft maintenance programs. As a result, the flying public may be taking an unforeseen risk when traveling internationally.

Aging aircraft has become an increasingly serious topic of study with the rise of aircraft fleets worldwide. The Federal Aviation Administration (FAA), for example, had set 2007 as the date to reduce the fatal accident rate by $80 \%$ from 1994-1996's data (Pappas, 2006). The useful age of an aircraft depends on many factors and can be defined by all or a combination of those factors: chronological age, the number of flight cycles, and the number of engine hours. The latter two factors may more directly impact the airworthiness of an aircraft. However, the chronological age can also affect the aircraft's operation (Australian Transport Safety Bureau, 2007). While there is no unified agreement as to how to define the age of an aircraft, all aviation authorities have a way to assess it. Some 
authorities have set limits on the age of the aircraft, while others have set limits on the number of previous owners amongst other limiting factors, such as age-related effects of corrosion (FAA, 2006).

This study focuses on commercial aircraft and utilizes data collected from the Aviation Safety Network's database of airline accidents. Nationality of carrier and the phase of flight the aircraft was in while the accident occurred was also taken into consideration. A total of 549 aircraft accidents qualified for the study during the period of 2000 to $2007 .{ }^{1}$ If the accident was found to be caused by external factors, such as a hurricane, hijacking, hanger catching on fire, the accident was excluded.

\section{INTERNATIONAL EFFORTS TO IMPROVE SAFETY MAINTENANCE PROGRAMS}

Globalization requires a high level of integration and standardization of all of the functional areas of an organization in order to minimize costs and maximize the distribution of increasingly homogeneous products. Therefore, a global product, such as an aircraft, is expected to have a certain level of standardization in safety regulations worldwide, and it appears that the industry, in general, is moving in that direction. A review of the literature revealed that there are several aviation organizations that are leading the way toward a possible standardization of safety maintenance practices worldwide. These are the Federal Aviation Administration (FAA), The Australian Transport Safety Bureau (ATSB), and the Joint Aviation Authorities (JAA).

The challenges of regulating the industry in the U.S. alone were apparent at the twentieth meeting of Directors of Civil Aviation of the Eastern Caribbean in December 2006. The Federal Aviation Administration (FAA) discussed new ideas for dealing with aging aircraft apart from determining how many operators an aircraft had in its lifetime. Some policies include limiting or prohibiting aircraft over a certain age, limiting the number of carriers that could have previously operated the aircraft, and requiring stringent inspections or maintenance practices. The FAA notes that if there was widespread adoption by many authorities of policies similar to these, the ability of both aircraft owners and operators to transfer aircraft to other carriers would diminish, regardless of the age. It also noted that these policies may be perceived as creating undue burden for operators and may prove inefficient for addressing aging aircraft safety.

The FAA trusts the certification programs of its bilateral partners as a way of ensuring the airworthiness of the aircraft of those countries. The FAA notes that many smaller civil aviation authorities have adopted limitations on the import of certain transport category aircraft, including restrictions in areas such as aircraft age, operational history, and maintenance history. What is not known is to what degree FAA (and JAA) type of maintenance programs are implemented around the world.

In short, the FAA has identified the use of aging aircraft as an important part of today's international air transportation expansion as well as being crucial to an airline's economic viability. A poorly maintained aircraft ages faster than one that is well maintained. Consequently, the FAA's Aging Airplane Program addresses the full gamut of issues known to cause significant degradation to the air worthiness of an aircraft, including structural aspects, corrosion prevention, repair assessments, mandated rules for the operation of aging aircraft, and miscellaneous airworthiness directives. Since the operation and maintenance of an aircraft is more important than the number of its previous owners, the FAA has concluded that maintenance programs can effectively combat incidents related to aging aircraft (FAA 2006).

The Australian Transport Safety Bureau (ATSB) has issued the most current and comprehensive report on aging aircraft. The report was commissioned to study flight safety and its relationship with aging aircraft and to study the best way to manage aging aircraft. The ATSB study notes that older aircraft, including some new aircraft that were grandfathered in based on older designs, were generally designed under less stringent standards. It concluded that older aircraft present safety implications and that the aging processes of aircraft need to be properly managed. Two methods were noted for properly managing aging aircraft: 1) retirement so the average age of the

\footnotetext{
${ }^{1}$ A total of 1416 accidents occurred during this period.
} 
fleet remains under 20 years, and 2) a comprehensive maintenance program. The European Aviation Safety Agency (EASA), as well as the FAA, have made similar conclusions (ATSB, 2007).

Europe's Joint Aviation Authorities (JAA) has been active in proposing legislation and methods for their member countries to effectively regulate and safely operate aging aircraft. The JAA's publication Leaflet No 11: Continued Airworthiness of Ageing Aircraft Structures, which is based on FAA recommendations, discusses five programs covering key structural issues that should be implemented or amended by the member nations. The programs include supplemental structural inspection, corrosion prevention and control, aging aircraft modification, repair assessment, and evaluation for widespread fatigue damage. The JAA makes recommendations on how a regulatory body should implement, update, and review these programs to ensure continued aviation safety (JAA, 2001).

\section{METHODOLOGY AND STATISTICAL ANALYSIS OF AIRLINE SAFETY}

The safe operation of an aircraft involves the interfacing of humans, machine and environment. An entire area of study has evolved to explain the mechanics and implications of this interface situation. This area of study, called human factors, not only focuses on the relationship between man and machine, but also on how humans react in this type of setting. It is important to learn how this man/machine interaction differs across various regions of the world. The intention is to learn from past examples in order to improve aircraft safety records worldwide.

There are risks involved in any form of transportation and air travel has proven to be the safest. However, due to the special nature of flight, the occurrence of an aviation accident or incident attracts substantial public interest. Airline safety has been a broadly discussed issue throughout the aviation community (Vasigh and Helmkay, 2002). As a result, information about airline accidents is widely disseminated throughout the industry.

The commercial airline accident data is retrieved from the Aviation Safety Network's database of airline accidents. ${ }^{2}$ The information was collected from different sources ranging from the International Civil Aviation Organization (ICAO), the National Transportation Safety Board (NTSB), to the World Airline Accident Summary. The model is based on a total of 549 aircraft accidents on data collected for the period from 2000 to 2007. ${ }^{3}$ This evaluation has been conducted in terms of the quantifiable objective variables that impact safety. These variables are: ${ }^{4}$ aircraft manufacturer (AC), age of aircraft (YR), phase of flight (PH), accident type (DM), severity of accidents, and the country where the aircraft was registered.

- $\quad$ Aircraft manufacturer (AC): Only commercial aircraft were considered for this study, thus general aviation aircraft (those with 19 and fewer seats), and military aircraft were excluded. The aircraft were divided into categories based primarily on their manufacture: Boeing, Airbus, Douglas Aircraft Company and others. ${ }^{5}$

- $\quad$ Age of aircraft (YR): The age of the accident was determined as the period from the year the accident occurred and the year the plane was manufactured. ${ }^{6}$

\footnotetext{
${ }^{2}$ The database is based on collected sources ranging from the International Civil Aviation Organization (ICAO), the National Transportation Safety Board (NTSB), the World Airline Accident Summary, as well as others.

${ }^{3}$ A total of 1416 accidents occurred during this period.

${ }^{4}$ The main contributing factor of the accident was examined to determine the aircraft's role in the accident. If the accident was found to be caused by external factors, such as a hurricane, hijacking, a hanger catching on fire, the accident was excluded. Specifically the age of the aircraft was not a contributing factor to the aircraft's resulting damage from the accident.

${ }^{5}$ The Concorde was excluded specially due to the small number of aircraft produced as well as the dependent nature of those accidents on external factors.

${ }^{6}$ No considerations were made for the month or day of either the manufacture or accident date as the manufacture date was not consistently specific to include the day and month.
} 
- $\quad$ Phase of flight $(\mathrm{PH})$ : The phase of flight the airplane was in while the accident occurred was recorded per the CAST/ICAO Common Taxonomy Team's definition of flight phases to keep with international and industry standards. ${ }^{7}$ The phases of flight were divided into the following subcategories:

- Unknown: Where the phase of flight was not able to be determined or was overall unknown.

- Standing: The aircraft has arrived at the gate, is at the gate, ramp or parking area, is prior to pushback or towing, and is stationary.

- Taxi: The aircraft is moving under its own power on the aerodrome surface prior to takeoff or after landing.

- Takeoff/Initial Climb: From the application of power to an altitude of 35 feet above the runway. Also, from the first prescribed reduction of power or end of the take-off phase until reaching 1000 feet above the runway or the visual flight rules (VFR) pattern.

- En Route: For instrument flight rules (IFR) from completion of the initial climb through cruise altitude through the completion of a controlled descent to the initial approach fix (IAF). For VFR from the completion of the initial climb through a controlled descent to VFR pattern altitude or 1000 feet above the runway.

- Approach/Landing: For IFR from the IAF to the beginning of the landing flare. For VFR from the end of the en route phase to the beginning of the landing flare. Also, from the beginning of the landing flare until the aircraft exits the runway, comes to a stop on the runway, or when power is applied for a takeoff in the instance of a touch and go.

- $\quad$ Accident type (DM): The main contributing factor of the accident was examined to determine the aircraft's role in the accident. If the accident was found to be caused by external factors, such as a hurricane and hijacking, the accident was excluded. All other accidents were determined to be either unknown, none, minor, substantial, written off, or destroyed. The written off category included aircraft that are missing, their wreckage not locatable, or the aircraft was substantially damaged and inaccessible.

- Severity of the accidents is divided in to the following categories

- Unknown 1

- None 2

- Minor 3

- Substantial 4

- Written off 5

- $\quad$ The country in which the aircraft was registered was also examined to determine whether any trends about safety in different parts of the world could be determined. The different geographical regions were North America, Latin America, Europe, Africa/Middle East, and Asia/Asia Pacific.

In summary, the study focuses on several important questions concerning the aircraft accidents, severity of the accidents, age of the aircraft involved in the accident and the geographical locations. These questions include:

- Is there a relationship between overall safety performance and aging aircraft accidents?

- Is there a relationship between severity of the accidents and the phase of flight?

- Is there a relationship between accidents and aircraft manufacturers?

\section{INTERNATIONAL ASPECTS OF AIRLINE ACCIDENTS}

Different regulatory bodies are involved in governing aircraft safety around the world depending on which country/region the aircraft is operating in (i.e. FAA, JAA). What is not known is the degree to which these regulations are being adopted by many of the airlines of the world, especially those serving mainly local markets. Therefore, it is reasonable to believe that safety and maintenance standards differ across various regions. By examining the accident rates in various regions of the world, we can determine whether different levels of safety exist.

\footnotetext{
${ }^{7}$ Commercial Aviation Safety Team (CAST) and International Civil Aviation Organisation (ICAO) have jointly chartered CAST/ICAO Common Taxonomy Team includes experts from aircraft and engine manufacturers, airlines, pilot groups, transportation safety boards, and other groups.
} 


\section{AGING AIRCRAFT}

In order to understand the problems surrounding aging aircraft and air transportation safety, it is necessary to examine past accident records. Many organizations and companies started aging aircraft programs to give special attention to aircraft that have exceeded their normal operational design life. However, with respect to aging aircraft, the available literature does not draw a clear link between aging aircraft and increased risk, presumably due to effective regulation programs and maintenance practices.

In 1988, the fuselage of an Aloha Airlines Boeing 737 failed at multiple points as the plane cruised above Hawaii. One flight attendant was sucked out of the plane when it suffered an explosive decompression, but the aircraft managed to land without further loss of life. As a result, the United States Congress authorized the National Aeronautics and Space Administration (NASA) to conduct an independent aging aircraft program in collaboration with the Federal Aviation Administration (FAA) and the aircraft industry. The problem of aging aircraft is a serious one and is addressed by the regulators and other agencies, including the airlines themselves. As a result of the Aloha Airlines crash, rigorous safety standards were put in place to inspect for metal fatigue on older aircraft with a large number of cycles (takeoffs and landings). However, it is clear that airlines need to be held more closely to these standards as it was revealed earlier this year that Southwest Airlines had missed some inspections on older 737s. Subsequent inspections found cracks on six of these aircraft (CNN, 2008).

\section{AIRCRAFT ACCIDENT DATA}

The commercial airline accidents between 2000 and 2007 are broken down by aircraft manufacturer, age of the aircraft, accident type, country in which the aircraft was registered, and the phase of operation in which the accident occurred. First, the raw accident data is analyzed and presented; then we normalize these figures and present the differences in population size.

I: $\quad$ Aircraft Manufacturers and Accidents:

The initial statistical investigation of the data surrounding the safety postures of Airbus, Boeing ${ }^{8}$ and McDonnell Douglas (MD), ${ }^{9}$ as defined by the number of accidents during the time frame of 2000 to 2007 was conclusive. Airbus has the lowest total number of accidents with only 27 occurring during the period of investigation (Table BN-1). ${ }^{10}$ The authors are cognizant of the fact that there is a difference between the number of aircraft in existence between the older Boeing and the relatively new Airbus. ${ }^{11}$ To make any conclusions, the number of aircraft was normalized with respect to operational fleets (Figure AN-1).

Table BN-1: Aircraft Accidents by Manufacturer

\begin{tabular}{|c|c|}
\hline Aircraft Manufacturer & Number of Accidents \\
\hline Boeing & 109 \\
\hline Airbus & 27 \\
\hline MD & 74 \\
\hline Others & 259 \\
\hline
\end{tabular}

\footnotetext{
${ }^{8}$ During the 1920 's and 1930 's, Bill Boeing, set forth the operations of his fledgling aircraft manufacturing company. Initially, Boeing built more fighter aircraft than any other company.

${ }^{9}$ MD had been in business since 1920, producing military aircraft, helicopters, missiles, and commercial aircraft. In 1997, it merged with Boeing to form The Boeing Company.

${ }^{10} \mathrm{BN}$ : Before normalizing.

${ }^{11}$ The corporation, created in 1970, began as a consortium between four leading European aerospace companies. Aerospatiale Matra of France, DaimlerChrysler Aerospace Airbus Gmbh of Germany, British Aerospace from Great Britain and CASA of Spain are all shareholders in the company.
} 
The number of accidents was normalized by manufacturer by dividing these numbers by the fleet of aircraft for each manufacture. After normalizing the number of aircraft in service, Airbus still has the lowest accident rate of the three major passenger aircraft manufacturers. Approximately 1 out of every 1,000 Airbus aircraft had an accident between 2000 and 2007. In contrast, McDonnell Douglas had the highest accident rate of the three major manufactures with approximately 14 out of every 1,000 aircraft having an accident between 2000 and 2007. The higher accident rate for McDonnell Douglas aircraft may be due to the fact that these are all older aircraft, with the last of the McDonnell Douglas aircraft (MD-11) being delivered in early 2001, four years after the merger with Boeing (Boeing, 2008).

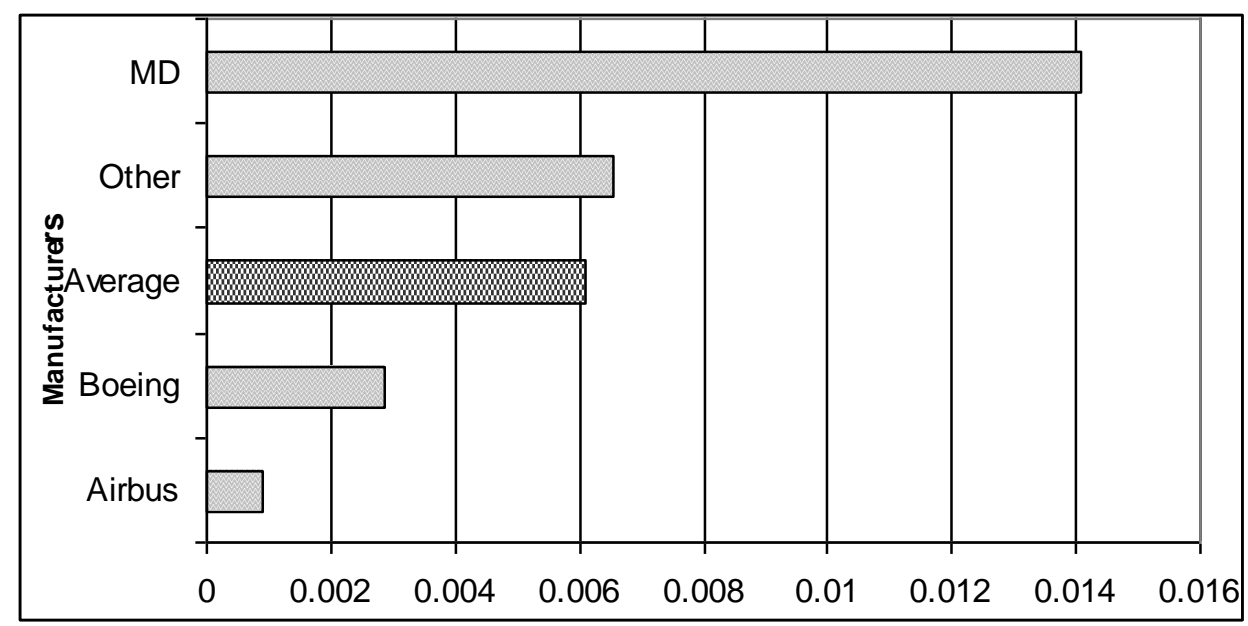

Figure AN-1 Accident Rates by Manufacturer (2000-2007)

Figure 2 and Figure 3 present the number of accidents by aircraft age. The aircraft were divided into ten age groups; each group representing a five-year age range (i.e. group 1 represents aircraft age $0-4$ years, group 2 represents 5-9 years old, etc.).

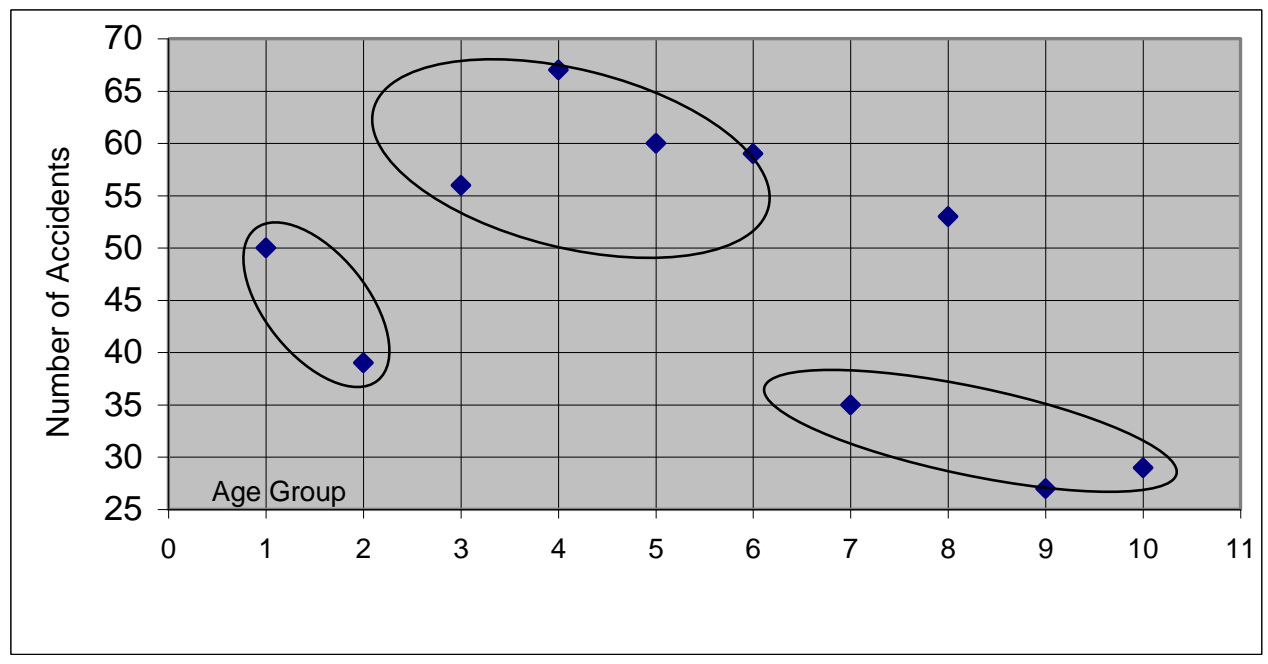

Figure 2: Distribution of Aircraft accidents by age (2000-2007) 
The data show that a higher level of accidents occur in aircraft that are between 15 and 29 years old. This is likely due to the higher amount of cycles on these aircraft and the constant maintenance that needs to be performed on older aircraft to keep them in perfect working condition. The reason that there are not as many overall accidents in aircraft over 30 years old is that by 30 years and above, most aircraft are retired. The overall number of aircraft in age category would be needed to normalize the data to see if the high accident rate of older aircraft increases after age 30 .

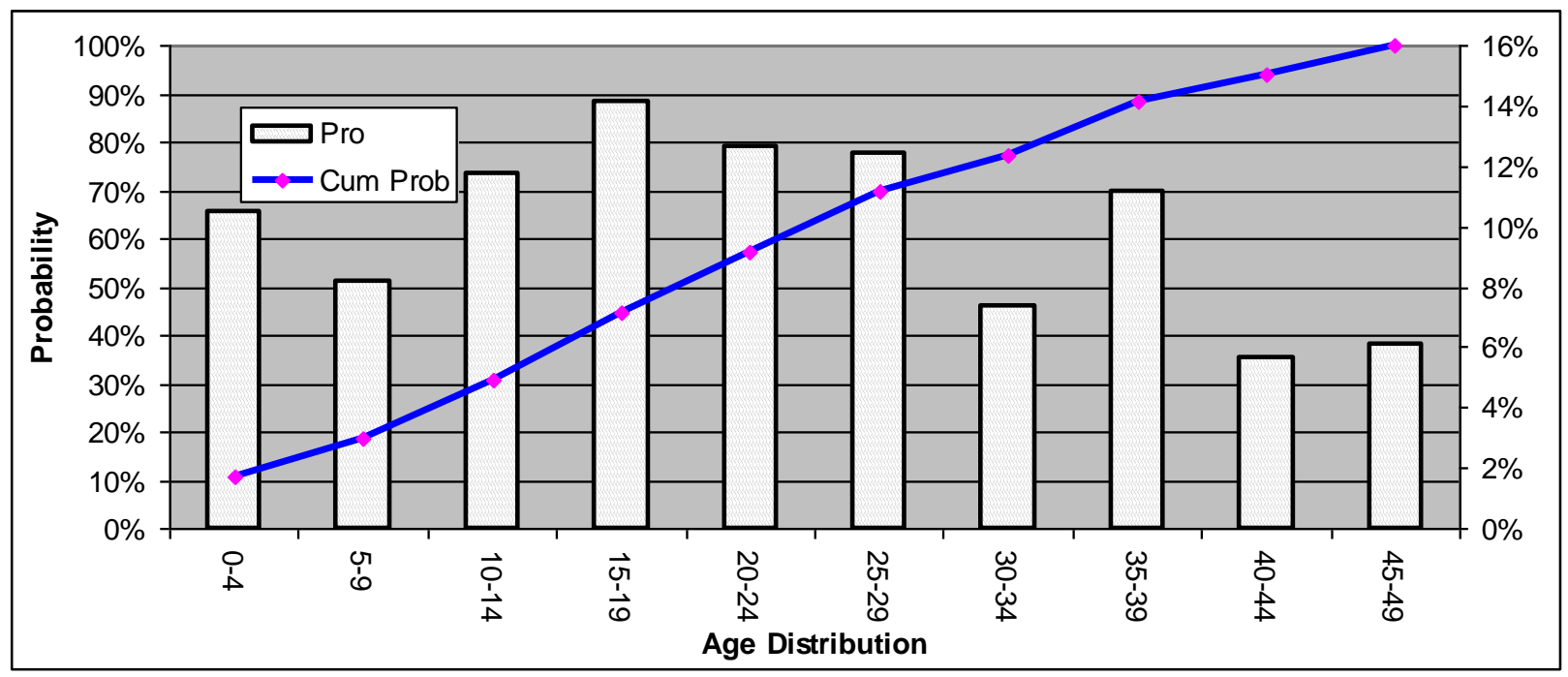

Figure 3: Distribution of aircraft accidents by age

There is a general increasing trend in the probability of an accident as an aircraft ages, though a dip exists after the 15-19 year age range. This is due to the overall number of aircraft flying at a certain age level begins to decline at 20 years. $^{12}$ The data suggests that the majority of airplane accidents occur around 20 to 24 years of age. New aircraft, while having a high occurrence, do not have a high mean of damage severity. This suggests that aircraft from 0 to 4 years of age experience less severe accidents than do those that are older.

Table BN-2 shows the raw accident numbers by region and Figure AN-2 normalizes this data using revenue passenger miles (RPMs). ${ }^{13}$

\begin{tabular}{|ccc|}
\hline \multicolumn{3}{|c|}{ Table BN-2: Aircraft Accidents by Region } \\
& Accidents & Probability \\
& 121 & $25.42 \%$ \\
North America (NA) & 60 & $12.61 \%$ \\
Latin America (LA) & 99 & $20.80 \%$ \\
Europe (EU) & 69 & $14.50 \%$ \\
Africa/Middle East (AF) & 127 & $26.68 \%$ \\
Asia/Asia Pacific (AP) & 476 & $100.00 \%$ \\
Total & & \\
& & \\
& & \\
\hline
\end{tabular}

12 In 1983, the Boeing Co. started an aging aircraft program to examine the safety of aircraft older than 20 years.

13 RPM is a measure of a passenger traffic for an airline flight calculated by multiplying the total number of revenue-paying passengers aboard the aircraft by the distance traveled measured in miles. 


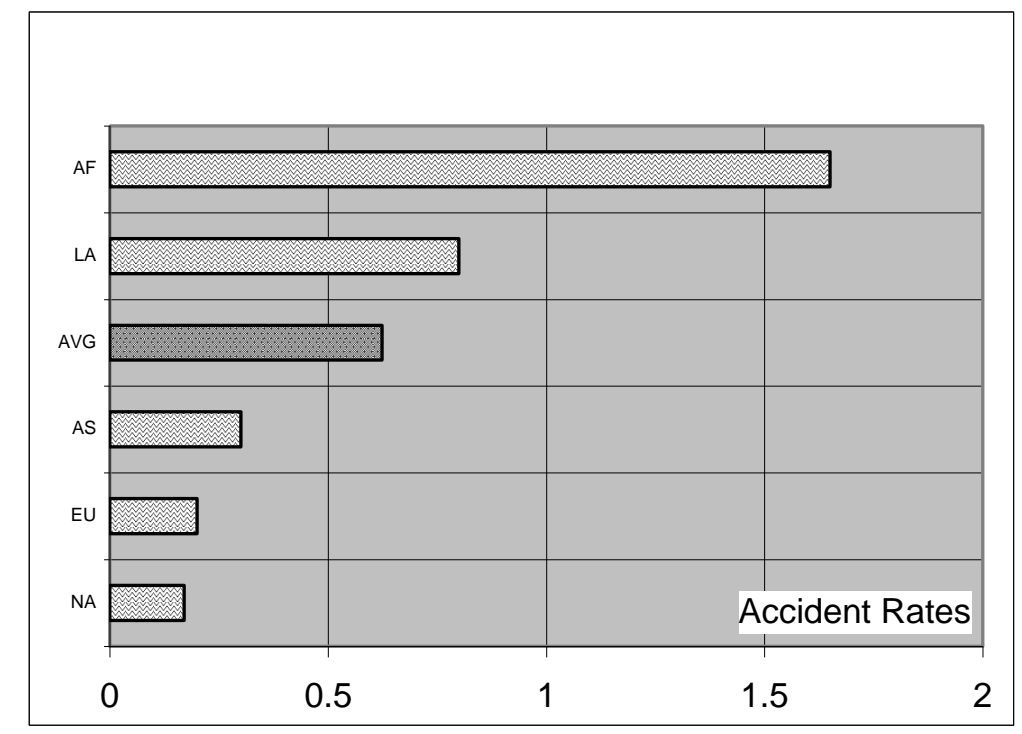

Figure AN-2: Accident Rate by Region

Source: Boeing Commercial Airplanes, 2007 and authors' compiled accident data

After normalizing by RPM, it is clear that a higher accident rate exists in Latin America and the Africa/Middle East region than the average of all five regions. The safety records in Africa and Latin America are by far the world's worst safety regions, and North America is the safest. The reason for the higher accident rate may be that safety standards or oversight are not as high in these areas of the world. Another plausible explanation is that airlines in these regions, especially Africa, typically use older, used aircraft which could be more likely to experience an accident. ${ }^{14}$ North America and Europe have the lowest accident rates, which can plausibly be explained by the fact that technology (i.e. weather radar, ATC) is more modern in these regions.

\section{II: $\quad$ Accident Severity and Phase of Flight:}

Accidents were examined on the basis of their severity and the phase of operation in which the aircraft was operating. Severity of accidents was divided into five categories based on damage to the aircraft; unknown, none, minor, substantial and written off. Accidents were given a numerical value for severity based on these categories ranging from 1-5 (1 being unknown, 5 being written off). The distribution of severity of accidents follows in Figure 4.

A majority (approximately 60\%) of the accidents that occurred caused substantial damage to the aircraft. The second most-likely severity to occur was minor damage to the aircraft (approximately 29\%). Less than 5\% of accidents resulted in the aircraft being written off. To examine severity of accidents further, manufacturers of aircraft were compared to see whether one manufacturer had an advantage that could, in general, result in an aircraft better withstanding the damage of an accident. The result of this analysis is shown in Table 3.

\footnotetext{
${ }^{14}$ Number of air crashes reaches a record low; Annual survey finds accidents at lowest since 1950s. The Daily Telegraph, pg \$9, January 21, 2004
} 


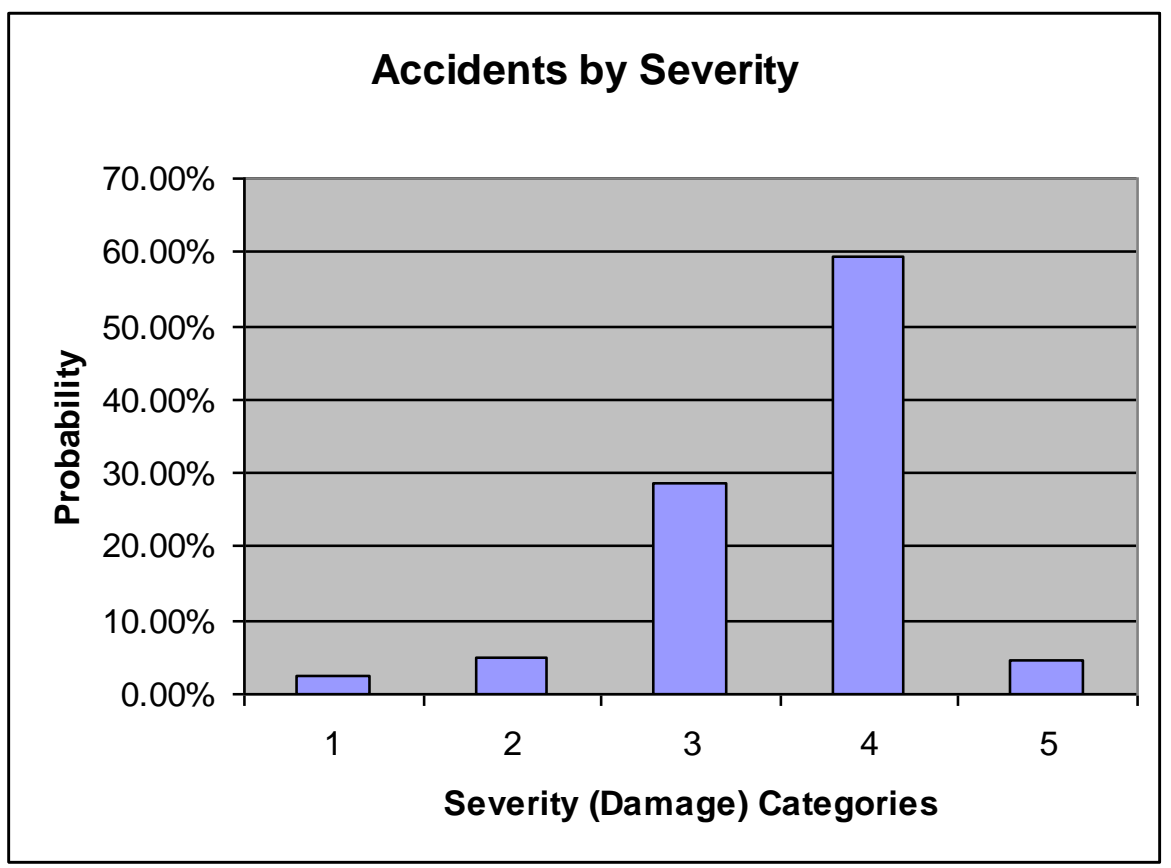

Figure 4: Accident Distribution by Severity

\begin{tabular}{|c|c|}
\hline \multicolumn{2}{|c|}{ Table 3: Average Severity by Aircraft Manufacturer } \\
\hline Manufacturer & Mean Damage \\
\hline Boeing & 3.54 \\
\hline Airbus & 3.25 \\
\hline McDonnell Douglas & 3.59 \\
\hline Other & 3.67 \\
\hline
\end{tabular}

The mean score illustrates that accidents for all manufacturers average between minor and substantial. However, Airbus' mean score is lower than the rest, Boeing being closer to minor rather than substantial. In addition to the mean damage, it is also important to determine whether a manufacturer is more likely to suffer a write-off of an aircraft after an accident. One can conclude that in general, the aircraft Airbus builds has fewer accidents and experience less damage when accidents occur (see also Figure AN-1).

The written-off and destroyed category for other aircraft manufacturers occurred with a greater disparity than with the Airbus, Boeing and McDonald Douglas manufacturers. With the other manufacturers, a 2.3 to 3:1 ratio of severe accidents to other accidents existed, whereas with Boeing, the ratio was only 1.5:1 and Airbus was 0.75:1. Thus, the accidents from other manufacturers were more likely to be severe than those from Boeing or Airbus.

Table 4: Aircraft Accidents by Phase of Operation

\begin{tabular}{|c|c|c|}
\hline Phase & \# of accidents & Percentage \\
\hline Standing & 21 & $4.41 \%$ \\
\hline Taxi & 10 & $2.10 \%$ \\
\hline Take-off & 54 & $11.34 \%$ \\
\hline Initial Climb & 19 & $3.99 \%$ \\
\hline En Route & 143 & $30.04 \%$ \\
\hline Approach \& Landing & 229 & $48.11 \%$ \\
\hline Total & 476 & \\
\hline
\end{tabular}


It is also important to study when accidents occur to determine where safety needs to improve. The phase of operation (flight) in which the accident occurred was studied to determine which phases of flight are most prone to accidents. Table 4 shows the breakdown of accidents by phase of operation.

Approach/Landing was the phase of flight in which the greatest number of accidents occurred. The pilots' increased workload during this phase of operation is a likely explanation for the high number of accidents. During approach and landing, pilots must communicate with Air Traffic Control, negotiate holding patterns, operate flaps and landing gear, and deal with weather and runway conditions. The interesting data here is that enroute or cruise is the phase of operation with the second highest number of accidents; this phase of operation is usually when the pilots have their lightest workload, so one might expect the accident rate to be lower. Possible explanations for the high number of accidents in this phase of flight include errors in communication/navigation (i.e. slamming into a mountain), major mechanical malfunctions (i.e. loss of hydraulics), and severe turbulence. Further analysis provided insight into the correlation of severity of accidents and phase of flight. A correlation analysis was completed to determine whether there was any relationship between the phase of flight in which the accident occurred and the severity of those accidents. Results of the correlation analysis are shown in Table 5.

\begin{tabular}{|c|c|c|}
\hline \multicolumn{2}{|c|}{ Table 5: Correlation Matrix between accident severity and phase of operation } \\
\hline & severity & \\
\hline severity & 1 & 1 \\
\hline phase & 0.60293 & \\
\hline
\end{tabular}

The matrix shows a $60 \%$ correlation between the severity of the accident and phase of flight. This means that there is a strong correlation between the phase of flight and how severe the accident will be. In this case, it can be interpreted that the phases of flight with the most accidents (Approach/Landing, etc.) will likely consist of the accidents which also result in the most damage.

\section{CONCLUSION}

Differences in aviation safety records around the world should be minimal or nonexistent considering the global nature of aviation. However, significant differences in safety records exist and the reasons for those differences require the attention of governments, regulatory agencies, aircraft manufacturers, airlines and the flying public. One concern is that aircraft are increasingly used beyond their designed economic life. The Aloha accident in 1988 forced all concerned to actively investigate the relationship between aging aircraft and safety. The FAA and JAA have been influential in the development and dissemination of safety programs around the world. However, their efforts have not yet resulted in a world-wide standardization of safety and maintenance programs. This may be an indication that while an aircraft may be a global product, the aviation industry lags behind in becoming a global industry.

This study focuses on the relationship between aging aircraft and region of the world where the aircraft were registered. A total of 549 aircraft accidents from 2000 to 2007 were used. The key variables are: aircraft manufacturer (AC), age of aircraft (YR), phase of flight (PH), accident type (DM), severity of accidents, and region of the world. The main aircraft manufacturers studied are Airbus, Boeing, and McDonnell Douglas. Findings demonstrate that Airbus has the lowest accident rate of any of the three major passenger aircraft manufacturers (approximately 1 out of 1,000) and McDonnell Douglas had the highest accident rate (approximately 14 out of every 1,000). The higher number of older aircraft built by McDonnell Douglas is thought to be a contributing factor. In general, accidents increase with the age of an aircraft, although a slight dip occurs after 19 years. This may be due, in part, because of the gradual phasing out of aging aircraft. This study also revealed that there is a correlation between the number of accidents, their severity, and aircraft manufacturers. One can conclude that the aircraft Airbus builds have fewer accidents and experience less damage when accidents occur. 
Although most regulatory regimes in charge of maintenance programs around the world are modeled after well established regulatory bodies, such as the FAA and JAA, it is unknown to what degree airlines around the world follow these models. The study demonstrates that higher accident rates occur in the regions of Latin America and Africa/Middle East than the average of all five regions studied (please see table BN-2). One may conclude that different safety regulations are being implemented in those regions.

While a lot has been done to internationalize safety and maintenance regulations, this study demonstrates that much needs to be done to reduce differences in safety that exist in various regions of the world. The question remains as to the best way to move toward a global standardization of aircraft maintenance programs. It is paradoxical that while an aircraft can be considered a global product, the standardization of aircraft maintenance programs would remain illusive. It is essential for the traveling public to trust the safety of an aircraft regardless of the region of the world the travel occurs.

\section{REFERENCES}

1. Australian Transport Safety Bureau. (2007). How Old is Too Old? The impact of ageing aircraft on aviation safety. Canberra City, AU: Australian Transport Safety Bureau.

2. Boeing. (2008). Boeing: History-Higher, faster, farther-McDonnell Douglas Corp...Goshawks and MDs. Retrieved May 16, 2008, from the Boeing Company: http://www.boeing.com/history/narrative/n085mdc.html

3. Boeing Commercial Airplanes. (2007). Current market outlook 2007: How will you travel through life? Retrieved May 8, 2008 from http://www.boeing.com/commercial/cmo/index.html

4. Borenstein, Severin \& Nancy L. Rose. (2007). "How Airline Markets Work...Or Do They? Regulatory Reform in the Airline Industry," NBER Working Papers 13452, National Bureau of Economic Research.

5. CNN. (2008). Southwest grounds 44 planes. Cable News Network, March 12, 2008. Retrieved May 16, 2008, from Cable News Network: http://www.cnn.com/2008/US/03/12/southwest.airlines/index.html?iref=newssearch

6. Dempsey, P. and L. Gesell. (1997). Air Transportation: Foundations for the 21 st Century. Chandler: Coast Aire Publications.

7. Dionne, G., Gagne, R., Gagnon, F., \& Vanasse, C. (1997). Debt, moral hazard and airline safety: an empirical evidence. Journal of Econometrics, 79, 379-402.

8. FAA. (2006). Controlling Fleet Growth and Managing Aircraft. Twentieth Meeting of Directors of Civil Aviation of the Eastern Caribbean, (p. 5). Miami, Fl.

9. JAA. (2001). Leaflet No 11: Continued Airworthiness of Aging Aircraft Structures.

10. Haight, F. A. (1994, January). Problems of estimating comparative costs of safety and mobility. Journal of Transport Economics and Policy, 28.

11. Mucha, H. J. (2004): Automatic Validation of Hierarchical Clustering. In: J. Antoch (ed.): Proceedings in Computational Statistics, COMPSTAT 2004, Physica-Verlag, Heidelberg, 1535-1542.

12. Oster, C. V., Jr., \& Strong, J. S. (1991). Risk tiers and safety mismatches in international aviation. Journal of the Transportation Research Forum, 32 (1), 73-85.

13. Pappas, R. (2006, September 7). Aging Aircraft Program. Retrieved November 18, 2007, from The Federal Aviation Administration: http://aar400.tc.faa.gov/Programs/AgingAircraft/index.htm

14. Scheraga, C. A., \& Ornstein, S. (1991). Market forces and airline safety: an empirical reevaluation. Transportation Research Forum, 31 (2), 278-285.

15. The Airline Monitor. (2006). Passenger aircraft in world airline fleets. July 2006.

16. Vasigh, B., Helmsky, S., "An Empirical Examination of Airframe Manufactures' Safety Performance: Boeing Versus Airbus." Journal of Public Works Management and Policy, Vol 5, Number 2, pp. 147-156, October 2000.

17. Vasigh, B., Helmsky, S., "An Evaluation of Regional Airline Safety in the New Regulatory Environment," Journal of Transportation Quarterly, Vol 54, Number 2, 59-76. Spring, 2000.

18. Vasigh, B., and Helmsky, S., "Airline Safety: An Application of Empirical Methods to Determine Fatality." Handbook of Airline Economics, Second Edition, PP 501-512, McGraw- Hill Company, 2002. 


\section{APPENDIX 1}

During the 1920's and 1930's, the former Pacific Northwest lumberman, Bill Boeing, set forth the operations of his fledgling airplane manufacturing company. Initially, Boeing built more fighter aircraft than any other company. After the commercial aviation industry began in earnest, with the introduction of private air carriers flying mail between cities, Boeing not only developed an aircraft for the purpose, but also won the contract for the mail rights between Chicago and San Francisco. The aircraft could carry five hundred pounds of mail as well as four passengers, hence the inauspicious introduction into the commercial air transport industry. To date, Boeing continues to develop and produce new 700-series aircraft, while continuing to improve upon old models, such as the 737 and 747 series. The merger with McDonnell Douglas in 1997 has also increased the product-line offering of the Boeing Company.

Airbus Industrie, on the other hand, has had a very different history. The corporation, created in 1970, began as a consortium between four leading European aerospace companies. Aerospatiale Matra of France, DaimlerChrysler Aerospace Airbus Gmbh of Germany, British Aerospace from Great Britain and CASA of Spain are all shareholders in the company. Fokker of the Netherlands, Alenia of Italy and Belairbus are also risk-sharing associate consortium members, dependent upon the project. The establishment of Airbus Industrie has been used as a shining example of corporate cooperation in the relatively new European Union. The firm itself has been built upon a single philosophy, which is to design and develop aircraft to fill market needs. Despite the inevitable difficulties of creating a competitive firm in a mature industry such as air transport production, Airbus has risen to the number two civil airliner producer in the world. Until January of 1999, this rise has been solely the result of airliner manufacturing.

McDonnell Douglas was the result of a merger between the McDonnell Aircraft Corporation and the Douglas Aircraft Company. In 1967, McDonnell Douglas was created, mostly due to the financial troubles of the two parent companies. While both companies had produced successful aircraft independently, their joint forces created several successful military aircraft including the Eagle and Hornet. Their commercial airplane development consisted of variations of its successful DC- 9 and DC-10 airplanes, which includes the MD-11, the MD-80 series, and the MD-90 series. McDonnell Douglas, though making commercial airplanes, was highly dependent on the defense market, which was shrinking in 1996. Furthermore, its commercial aircraft division took a negative hit with the ValuJet flight 592 (DC-9) crash in 1996. No new orders for the MD-95 were placed after the accident. McDonnell Douglas also cancelled plans to produce a long-range jetliner, the MD-XX. It also lost the Joint Strike Fighter contract, and American Airlines, its largest commercial customer, announced plans to purchase Boeing aircraft. McDonald Douglas then made a deal to produce an aircraft with Boeing, which eventually turned into talks of a merger between Boeing and McDonnell Douglas' CEOs. A $\$ 13.3$ billion agreement was reached, and McDonnell Douglas formally became part of Boeing in 1997. 